\title{
Ecos de um totalitarismo brasileiro: entrevista com Bernardo
}

Kucinski

\author{
Sergio SCHARGEL* \\ Universidade de São Paulo (USP) \\ Camila Wielmowicki UCHOA** \\ Pontifícia Universidade Católica do Rio de Janeiro (PUC-Rio)
}

Bernardo Kucinski tem muitas facetas criativas. É jornalista de formação, já foi professor de Comunicação da ECA-USP. Também atuou como Assessor Especial da SECOM durante o governo Lula e, finalmente, hoje se dedica ao seu lado literato. Apesar de sua longa carreira na comunicação e com diversos livros publicados, estreou na ficção em 2011, com K.: relato de uma busca, obra de inspiração autobiográfica em que narra a busca de seu pai por sua irmã, desaparecida na ditadura militar. Em seguida, publicou um livro de contos e $O s$ visitantes, este último retomando eventos de $K$.

Em 2019 Kucinski publicou A nova ordem, ficção distópica que imagina um Brasil com uma ditadura militar totalitária. Uma vez mais, assim como $K$., A nova ordem flexibiliza as fronteiras do real e do ficcional, ao ecoar, a despeito do autor buscar uma distância, aspectos visíveis no bolsonarismo. Nesta entrevista realizada no

\footnotetext{
* Doutorando em Letras pela USP, doutorando em Comunicação pela UERJ, doutorando em Ciência Política pela UFF. Mestre em Letras pela PUC-Rio, mestrando em Ciência Política pela UNIRIO. Bacharel em Comunicação Social, Jornalismo e Comunicação Social, Publicidade e Propaganda, amba s pela PUC-Rio, bacharelando em Letras pela Estácio de Sá. Bolsista CAPES. Sua pesquisa e produção artística são focadas na relação entre literatura e política, tangenciando temas como teoria política, literatura política, pós-memória, antissemitismo e a obra de Sylvia Serafim Thibau. E-mail: sergioschargel_maia@hotmail.com

** Doutoranda em Letras na PUC-Rio, no programa de Literatura, Cultura e Contemporaneidade. Atualmente desenvolve parte da pesquisa do doutorado no departamento de Belas Artes da Universidade do Porto, em Portugal. No departamento de Letras da PUC-R io é integrante do grupo de trabalho dos Eventos Acadêmicos e uma das organizadoras do evento anual discente Letras Expandidas. Mestre em Comunicação na PUC- RJ.Possui graduação em História da Arte pela Universidade do Estado do Rio de Janeiro e Licenciatura em Artes Visuais pela AVM/ Cândido Mendes. Tem experiência na área de Artes, com ênfase em Teoria da Arte. Já atuou na área de produção e organização de exposições, eventos culturais e feiras de arte, projetos de editais para a unidade a cadêmica, assessoria em pesquisa s de moda, produção de textos curatoriais e tem experiência também na área de educação, a lém de possuir uma produção como artista visual. Atualmente trabalha com curadoria independente e projetos educacionais e voluntariado com crianças em colégios na cidade do Porto. Email: camiuchoa@gmail.com
} 
dia 30 de julho de 2020 por e-mail, Kucinski falou um pouco sobre sua carreira literária, causas e efeitos de A nova ordem e o eco do bolsonarismo em sua ficção.

1- A sua carreira foi marcada por uma relação entre jornalismo e política, e mais recentemente também com a literatura. Qual a sua relação com a política? Como você se encaminhou para a literatura? Por que a ficção foi uma opção tardia na sua carreira?

Encaminhei-me para a literatura num momento especial em que, recém-saído da assessoria do governo Lula, vi-me também "saído" da universidade pela aposentadoria compulsória aos 70 anos. Minha relação com a política sempre se deu através da prática de um jornalismo crítico, independente e fundado no conhecimento, mesmo quando servia o governo Lula. Hoje lamento ter tentado a ficção tão tardiamente. Não tentei antes porque me realizava plenamente no jornalismo e numa fase posterior, também na academia, em especial no ensino do jornalismo.

2- Qual a relação de $K$. com a narrativa de Franz Kafka? Há inspiração ou relação com o Joseph K. de $O$ processo ou o personagem $\mathrm{K}$ de $O$ castelo?

A relação nasceu naturalmente, sem que eu percebesse. No meu surto literário porque foi mesmo um surto - um dos primeiros contos chama-se justamente $O$ processo. O cenário é de um sistema burocrático e o personagem é um senhor K. que recebe uma convocatória desse sistema. Não tem nada a ver com o K. do romance. Mas é daí, creio, que surgiu a idéia de adotar K, como personagem do romance.

3- Partindo do nosso presente, podemos identificar que $K$ estabelece uma relação com um passado traumático e $A$ nova ordem com um futuro distópico terrível. $A$ nova ordem é um desdobramento de $K$ ? Como você vê a junção desses tempos traumáticos no nível individual e geracional?

Não, A nova ordem não é um desdobramento de $K$. São processos criativos totalmente distintos. $K$. foi a forma que eu encontrei para processar um trauma 
pessoal. O desdobramento de $K$. é Os visitantes, editado pela Companhia das Letras, em que personagens de $K$. visitam o autor para reclamar ou divergir do que foi escrito. Em A nova ordem há um distanciamento entre escritor e escrita. A narrativa é deliberadamente inverossímil para produzir o efeito desejado. Nessa altura já assumo o ofício de escritor. Já não é uma catarse, como K. É escrita cínica e fria. A nova ordem é uma montagem de textos que eu já tinha escrito anos antes, inícios de histórias que não terminei na época, e que decidi juntar e amalgamar com alguma coisa mais, para intervir no momento atual. É uma novela de intervenção.

4- Até que ponto a sua vivência e da sua família influenciaram na composição da distopia? Qual o papel das instituições (sobretudo o sagrado e a ciência) na distopia contemporânea? Seria uma maneira de expiar uma culpa, pagar uma dívida com o passado?

Minha família, especialmente meu pai que foi escritor na língua iídiche e também militante político, tiveram grande influência na minha formação. Mas nosso ambiente era então de utopias e não de distopias. Duas utopias disputaram os corações e mentes na minha juventude, a utopia socialista e a utopia sionista. Creio que minha distopia se inspira no Holocausto (do que meus pais nunca falavam) e nos crimes de Stalin (desses, sim, meu pai falava). A primeira cena da A nova ordem é uma referência direta ao assassinato dos escritores judeus por Stalin e ao mesmo tempo ao Holocausto. A cena do fuzilamento dos cientistas é a reprodução fiel das execuções nazistas. É o real tão enlouquecido que nos parece distópico.

5- Como surgiu a ideia de $\boldsymbol{A}$ nova ordem? Você já tinha em mente escrever sobre uma distopia ou a ideia ocorreu a partir das eleições de 2018 ?

Já tinha em mente muito antes do Bolsonaro. A história estava quase toda escrita. O Bolsonaro entra nos rodapés.

6- É interessante, em $A$ nova ordem, como o absurdo se torna uma forma de humor. E o curioso é que isso é uma estética que se nota em outras obras que 
tratam de movimentos totalitários, autoritários ou fascistas, como $\mathrm{Na \tilde {o }}$ vai acontecer aqui, de Sinclair Lewis, e Ele está de volta, de Timur Vermes. Por que você decidiu permear o texto com esse humor sarcástico? Qual é a função do humor na estética do seu livro? Qual a relação entre horror e humor em $A$ nova ordem?

A ironia e o sarcasmo já estão nos meus contos Você vai voltar pra mim. Não sei explicar o motivo. Estão muito mais ligados ao estado de espírito ao escrever, à relação com a própria escrita. Talvez porque, naquele caso, eu via o absurdo de certa linguagem canônica das esquerdas, da crença na inevitabilidade do socialismo e outros dogmas. Sempre me senti um pouco distante dessa linguagem, justamente devido à minha formação acima de tudo crítica. Na minha última novela Julia, que trata das mesmas situações, já não aparece esse sarcasmo nem essa ironia, porque meu estado de espírito é outro.

7- Um ponto que me chamou atenção em $A$ nova ordem é a importância do controle mental para a manutenção do regime. Hannah Arendt fala em Origens do totalitarismo que o sonho de qualquer totalitarismo, em última análise, é o controle mental. Se no stalinismo esse controle se dava pelo puro terror, em sua obra ele atinge um aspecto literal: há, de fato, um chip controlando a mente. $O$ seu objetivo, ao colocar esse ponto no enredo, era traçar um paralelo com esse ponto de Arendt e com o próprio stalinismo/nazismo? Qual é a importância dessa questão para o enredo? Apesar de Ariovaldo acabar internado, com condição psicológica deteriorada, o final da história deixa certa dúvida sobre o destino da Nova Ordem. Além da questão do controle mental no totalitarismo, acho que é possível traçar um paralelo com o conceito de banalidade do mal. A nova ordem não permite que as pessoas enxerguem a gravidade da violação humana praticada, pois relativizam as situações e veem seus atos apenas como um cumprimento de ordens estabelecidas por seus superiores. Nesse sentido, seria possível uma tomada de consciência por parte destes que foram cooptados por esse sistema? Como se daria uma reconstrução dessa sociedade, em um suposto colapso? Como superar um mal banalizado? 
Eu nunca concordei com a tese da "banalidade do mal." Acho que foi um jogo de palavras e, como tal, de grande sucesso. Mas, além de falho em si mesmo, acabou sendo apropriado de forma simplista ou equivocada, o que o torna ainda menos aceitável. As torturas de Fleury não eram banais. Fleury não era um ser banal. A Casa da Morte não foi banal. Bolsonaro talvez seja um caso único em que o mal é personificado por um ser totalmente banal, insignificante, medíocre. É a exceção que confirma a regra. Toda a história de chips de controle de minha novela foi surgindo no andar da carruagem, durante o próprio processo de criação. Não estava nada planejado. Eu me diverti muito escrevendo essas partes. Não me inspirei em grandes teóricos, nem tive intenções de traçar paralelos.

Não creio em reconstrução. Colapso da Nova Ordem pode haver, por suas próprias limitações e contradições. Porém não será uma volta aos anos 50 de Juscelino ou à era Lula, de Luz Para Todos, Minha casa Minha Vida, Prouni e Bolsa Família. O povo brasileiro regrediu aos tempos de formação do país, em que se capturavam índios a laço, se escravizavam negros e se queimavam hereges na fogueira. Mais do que nunca, os bandeirantes são os nossos heróis.

\section{9- Em seu livro você tinha a in tenção de representar um totalitarismo, um fascismo} ou ambos? Quais são, para você, as diferenças entre esses sistemas políticos? É correto falar que o bolsonarismo é uma espécie de fascismo? Pelo tema do seu livro e pelo momento em que vivemos, você sof reu algum ataque após a sua publicação?

O bolsonarismo é uma forma de fascismo. O bolsonarismo é um fascismo infantilizado, vulgar e medíocre. Hitler foi tragédia, Bolsonaro é a farsa. Contudo, exerce o mesmo papel do fascismo original, de destruir as organizações populares e de trabalhadores, para atender o capital. Não sofri nenhum ataque devido à publicação de $A$ nova ordem. Foi recebida com solene desdém.

10- Por que você escolheu usar o termo "cientologia"? Foi intencional, em uma relação direta com a religião chamada Cientologia ou somente a coincidência do nome? 
Isso, sim, já é inspiração direta do bolsonarismo. Quis glosar os sistemas de conhecimento que se pretendem científicos, e não passam de crenças.

11- Fale um pouco sobre o caminho narrativo em "A nova ordem". Por que a opção de um deslizamento do discurso do narrador, que por vezes assume a voz de outros personagens, se confunde, se funde a elas ou dá lugar para essas outras vozes?

A nova ordem contém alguns blocos ou capítulos, como o primeiro, no qual os cientistas são fuzilados, que funcionam como contos, são autossuficientes. Foram escritos em tempos distintos. Um deles, o do Ariovaldo, acabou se mostrando ad equado para servir de fio condutor. E assim foi feito. É o mesmo processo criativo de K.O deslizamento do discurso tem a ver como esse processo. Um bloco pode ser um monólogo, o outro um diálogo, outro em terceira pessoa, ou com narrador onisciente, etc.

13- É curioso o personagem do Capitão Messias, que tem muitas semelhanças com Jair Bolsonaro. Além do segundo nome igual, ambos possuem a mesma patente e o gosto por armas. Por que colocar essa figura?

Trata-se de pura coincidência. Não tem nada que ver com o capitão Bolsonaro. Se tivesse me ocorrido a coincidência, teria escolhido outro nome.

14- Outro aspecto interessante são as idiossincrasias do totalitarismo brasileiro que você criou. A relação com as religiões neopentecostais, evidenciadas por alguns dos éditos que transformaram cinemas e teatros em templos, é algo estranho a outros formatos de totalitarismos. Para você, quais aspectos um totalitarismo brasileiro apresentaria em uma versão real? Teria como base um estado paternalista?

Nosso totalitarismo tem mais de escravagista e menos de paternalista. 